\title{
Oh, The Things You Don't Know: Awe Promotes Awareness of Knowledge Gaps and Science Interest
}

\author{
Jonathon McPhetres \\ University of Rochester
}

Word count: 8,091

Jonathon McPhetres, M.A. is a Ph.D. candidate in Social Psychology at the University of Rochester in Rochester, New York.

Correspondence concerning this article should be addressed to Jonathon McPhetres, Department of Clinical and Social Sciences in Psychology, University of Rochester, Rochester, NY 14627. Email: j.mcphetres@rochester.edu Phone: 1-585-275-9274

\footnotetext{
**This is the pre-print version of a manuscript published in Cognition \& Emotion.** The typeset version can be accessed at: https://www.tandfonline.com/doi/full/10.1080/02699931.2019.1585331
}

\section{Please cite this research as follows:}

McPhetres, J. (2019). Oh, The Things You Don't Know: Awe Promotes Awareness of Knowledge Gaps and Science Interest. Cognition \& Emotion. DOI: $\underline{10.1080 / 02699931.2019 .1585331}$ 


\begin{abstract}
.
Awe is described as an a "epistemic emotion" because it is hypothesized to make gaps in one's knowledge salient. However, no empirical evidence for this yet exists. Awe is also hypothesized to be an antecedent to interest in science because science is one way to fill those knowledge gaps. Results from four pre-registered studies $(N=1,518)$ indicate that manipulating awe through online (Studies 1a, 1b, and 1c) and virtual reality (Study 2) videos, led to greater awareness of knowledge gaps. Awareness of knowledge gaps was consistently associated with greater science interest and to choosing tickets to a science museum over tickets to an art museum (Study 1b). These effects were not consistently observed on, nor moderated by, other measures related to cognition, religion, and spirituality. However, exploratory analyses showed that science interest was better predicted by positive emotions than by awe. Still, these results provide the first empirical evidence of awe as an "epistemic emotion" by demonstrating its effects on awareness of knowledge gaps. These findings are also extended to the effects of awe on science interest as one possible outcome of awareness of knowledge gaps.

Keywords: awe; science interest; metacognition; emotion; pre-registered; open-data; open-materials.
\end{abstract}


"He to whom this emotion is a stranger, who can no longer pause to wonder and stand rapt in awe, is as good as dead: his eyes are closed.” -Albert Einstein (1931)

The joy of science lies in pondering the magnificent and seeking answers to the unknown. Indeed, Stephen Hawking's advice to "Look up at the stars and not down at your feet... Be curious." (Jha, 2012) is not far from what other scientists have noticed drives many scientific discoveries: the experience of awe. Awe has been described as an "epistemic emotion" and is hypothesized to fuel our pursuit of knowledge and understanding (Keltner \& Haidt, 2003) and it is further proposed that awe may be an important emotional antecedent to interest in science (Valdesolo, Shtulman, \& Baron, 2017). The reasoning behind this is that awe may make one aware of gaps in their knowledge, which leads one to seek out some epistemic framework to fill those gaps. Science is one such framework that provides a way of learning about our natural world. However, despite much theorization about the effects of awe, no research has investigated the link between awe and knowledge or interest in science. In the present studies, these relations are tested directly.

Awe as an emotion

Researchers have studied awe for decades. For example, it was posited that awe may meet the requirements of a basic emotion (Ekman, 1992), and others described awe as leading to interest and curiosity (Izard, 1977; Frijda, 1986). More broadly, awe is also a positive emotion. it has been argued that positive emotions, including awe, serve to broaden one's thoughts, actions, and awareness, leading them to explore new behaviors, and build new skills and resources (Fredrickson, 1998, 2013). Though awe is theorized to function in line with other positive emotions, researchers have argued it may be unique in some respects. For example, other researchers have characterized awe as an experience which turns our attention away from us to 
external events whereas general positive emotions may instead cause us to focus on ourselves (Shiota, Thrash, Danvers, Dombrowski, 2017). Still others have focused on how emotions similar to awe can promote prosociality (Prade \& Saroglou, 2016; Shiota, Campos, Oveis, Hertenstein, Simon-Thomas \& Keltner, 2017) and self-transcendence (Chirico \& Yaden, 2018).

Awe has been conceptualized as having the two central characteristics of perceiving vastness and needing accommodation (Keltner \& Haidt, 2003). That is, relying on Piaget's (1971) cognitive theories, Keltner and Haidt proposed that when we encounter information which does not fit into our current expectations (e.g., perceptually vast stimuli), we must change our existing schemas and "accommodate" this information. Thus, many researchers have referred to awe as a 'knowledge emotion' (Keltner \& Haidt, 2003; Silvia, 2010; Valdesolo et al., 2017). This theoretical conceptualization has laid the groundwork for more recent research on awe, which has directly investigated what kinds of stimuli elicit awe and what effects awe has on psychology. However, the proposed relation between awe and knowledge has not been directly tested.

What causes awe? A variety of "perceptually vast" stimuli reliably elicit awe, meaning such stimuli are magnificent and grandiose. One of the earliest experiences that would eventually come to be associated with 'awe' is when astronauts view the earth from space, referred to as the overview effect (Linenger, 2000; White, 1987; Yaden et al., 2016). Researchers have documented that when astronauts are able to view the entire earth at once they have a strong emotional response, they feel an overwhelming sense of self-transcendence, and experience strong identification with all of humankind. Simulated experiences of space travel also elicit the experiences of awe and wonder (Gallagher, Reinerman-Jones, Sollina, \& Janz, 2014). These experiences are similar to how awe is discussed theoretically. 
Many other stimuli have been noted to lead to awe in experimental settings. For example, videos of space and nature (Valdesolo \& Graham, 2014; van Elk, Karinen, Specker, Stamkou, \& Baas, 2016), viewing tall trees in nature (Piff, Dietze, Feinberg, Stancato, \& Keltner, 2015), viewing a fossilized skeleton of Tyrannosaurus rex (Shiota, Keltner, \& Mossman, 2007), or even just thinking about magnificent and grandiose scenes in nature (Griskevicius, Shiota \& Neufeld, 2010; Van Cappellen \& Saroglou, 2012) have all been shown to elicit awe. Further, virtual reality technology has been noted to be a strong inducer of awe (Chirico et al., 2017; Chirico, Ferrise, Cordella, \& Gaggioli, 2018; Gallagher, et al., 2014) likely because it presents perceptually vast stimuli in an immersive and realistic format.

What effects does awe have? Recent research has begun to investigate the unique outcomes of awe. For example, some research has shown awe is associated with experiencing uncertainty (Shiota et al., 2007; Valdesolo et al., 2014). Other research has focused on how the experience of awe makes one feel small or insignificant (van Elk et al., 2016) and how this experience can promote prosocial behaviors (Piff et al., 2015) and feelings of connectedness (Van Cappellen \& Saroglou, 2012).

However, none of this research has directly tested the main conceptualization of awe as an "epistemic emotion." As mentioned above, the experience of awe is also hypothesized to lead to a greater awareness of gaps in one's knowledge. One additional outcome of this awareness of knowledge gaps may be the desire to fill these gaps and science may be particularly suited for this. Again, such a relation has been hypothesized but not tested.

\section{The Present Studies}

In the present studies, it was expected that the experience of awe would lead to increased awareness of knowledge gaps and interest in science. In Study 1b, it was also expected that an 
increased interest in science could be observed by choosing tickets to a science museum over an art museum. Study 2 extended the findings and tested whether providing information about the awe-inducing event would resolve the knowledge gaps and diminish science interest—-that is, whether further information would help participants accommodate the experience into their existing schemas (Keltner \& Haidt, 2003). Several personality-level variables were examined as moderators of the relation between awe and interest in science but, because these are tangential to the main focus, these are described in the supplementary materials.

\section{Studies 1a-1c}

Studies $1 \mathrm{a}$ and $1 \mathrm{~b}$ were conducted simultaneously. Materials and procedure were identical with the exception that Study 1a was conducted online with a larger sample size and Study $1 \mathrm{~b}$ was conducted in the lab. Study $1 \mathrm{~b}$ included an additional outcome: choice of tickets to a science museum over tickets to an art museum. Study 1c was conducted as a large scale direct replication of $1 \mathrm{a}$ (and $1 \mathrm{~b}$ ). For each study, it was predicted that those in the awe condition (versus a control condition) would report greater awareness of knowledge gaps which would lead to greater interest in science and to choosing tickets to the science museum. The hypotheses, analyses, and sample sizes were preregistered with the Open Science Framework prior to data collection: (https://osf.io/r4ayh/?view_only=76150450c5024484aba61c1aa168336b).

\section{Participants}

Study 1a. In Study 1a, 366 (175 female) participants were recruited through Amazon's Mechanical Turk. Due to an error, other demographics were not collected. Sample size was based on a power analysis with the goal of detecting small $(d=.30)$ differences between two conditions with $80 \%$ power. A small effect size was chosen because this is a new effect and to ensure that smaller relations could be detected (of course, a smaller effect may not yield a p- 
value of less than .05). Eleven participants provided only partial data so, as noted in the preregistration form, partial data were treated using list wise deletion procedures so degrees of freedom differ in some analyses.

Study 1b. In Study 1b, due to funding limitations, 90 participants were recruited. Subjects were 18 male and 75 female (1 indicated other gender) undergraduates with an average age of $20.38(S D=1.78)$ and were compensated with their choice of museum ticket and some also received extra course credit.

Study 1c. Participants for Study 1c were recruited from the Prolific online survey platform. A power analysis indicated that a sample of 766 would allow for detection of effects as small as $d=.18$ between two conditions using a one-sample t-test. To account for exclusions, this sample size was exceeded and 900 subjects were targeted for recruitment. Fifty subjects were excluded for failing at least one attention check $(n=6)$ or because of problems with video or not listening to the audio $(n=45)$ resulting in a final sample of 850 with an average age of $34.15(S D=12.06)$.

\section{Materials and Procedure}

Studies 1a-c followed the same procedure with the exception that Studies 1a and 1c were online and, in Study 1b, participants were seated in a private laboratory cubicle. Participants were randomly assigned to one of two groups. In the awe condition, participants watched a video from BBC's Planet Earth (https://www.youtube.com/embed/3voeYWCAE2s?) intended to elicit awe (this video was slightly modified to increase quality for Study 1c:

https://youtu.be/R3qpluJb6pE). In the control condition, participants watched a humorous video from BBC's Walk on the Wild Side (https://youtu.be/EQ1HKCYJM5U). Both videos have been 
used in prior research (e.g., Valdesolo \& Graham, 2014; van Elk, 2016), both videos depict scenes of from nature, and both contain music.

Participants then responded to 9 items measuring general mood in randomized order, within which a single item measuring awe was used as a manipulation check. This was done in an attempt to avoid demand characteristics with some awe measures. However, no specific pattern of results was expected for these other emotion items and no analyses were planned. In randomized order, participants then responded to a 7-item measure of knowledge gaps awareness (see supplementary materials; items were written to follow a format similar to that used by Schraw and Dennison's (1994) metacognitive awareness scale; e.g., I ask myself if I really understand how the natural world works; This activity makes me realize how much I don't know about nature) and to an 8-item measure of science interest (Harty \& Beall, 1984; e.g., Science magazines and stories are interesting). In Study 1b, participants then indicated whether, for compensation, they would like to receive a ticket to the local science museum or a ticket to the local art museum. Both museums are the same distance from campus and tickets cost approximately the same price (\$7 and \$10).

For studies $1 \mathrm{a}$ and $1 \mathrm{~b}$ only, participants then responded to three individual difference measures in randomized order: the 10-item belief in science scale (Farias et al., 2015), the 7-item Cognitive Reflection Test (Toplak, Stanovich \& West, 2014), and the Need for Cognition scale (Caccioppo \& Petty, 1982). These were not included in Study 1c for brevity. At this point, participants also responded to an (exploratory) attention check question about the video (see supplementary materials). Finally, participants reported demographics and, in 1a and 1b, religiosity (Shariff, Cohen, \& Norenzayan, 2008) and spirituality (Piedmont, 1999).

\section{Results}




\section{Study 1a}

Manipulation check. Zero-order correlations are displayed in the top half of Table 1. As a manipulation check, a t-test indicates that those in the awe condition reported greater awe versus the control condition (see Table 2). Other emotions also differed between the two conditions, though the magnitude was much smaller (see Table 2).

Table 1.

Zero-order correlations between all variables in Studies $1 a$ and $1 b$.

\begin{tabular}{|c|c|c|c|c|c|c|c|c|}
\hline & 1 & 2 & 3 & 4 & 5 & 6 & 7 & 8 \\
\hline 1. Awe & - & $.23^{\star *}$ & $.40^{\star *}$ & .03 & $.14^{* *}$ & $-.15^{\star *}$ & $.17^{\star *}$ & $.24^{* *}$ \\
\hline 2. Science interest & $.21^{*}$ & - & $.53^{\star *}$ & $.36^{* *}$ & $.42^{* *}$ & $.14^{* *}$ & -.09 & .10 \\
\hline 3. Knowledge gaps & $.36^{*}$ & $.46^{\star *}$ & - & $.25^{\star *}$ & $.27^{* *}$ & -.05 & .05 & $.25^{\star *}$ \\
\hline 4. Belief in science & $-.23^{*}$ & $.39^{\star \star}$ & .13 & - & $.29^{\star *}$ & $.17^{* *}$ & $-.54^{\star *}$ & $-.35^{* *}$ \\
\hline 5. Need for cognition & -.04 & $.44^{\star *}$ & .15 & $.21^{*}$ & - & $.22^{* *}$ & $-.23^{\star *}$ & -.09 \\
\hline 6. 7-item CRT & -.16 & .13 & -.16 & $.21^{*}$ & $.25^{\star}$ & - & $-.21^{* *}$ & $-.27^{* *}$ \\
\hline 7. Religiosity & $.26^{*}$ & -.09 & .04 & $-.57^{\star *}$ & -.04 & $-.23^{*}$ & - & $.65^{\star *}$ \\
\hline 8. Spirituality & $.30^{* *}$ & .09 & .11 & $-.47^{\star \star}$ & .04 & $-.21^{*}$ & $.66^{\star *}$ & - \\
\hline
\end{tabular}

Note: Correlations in top half are from Study 1a, correlations in bottom half are from Study 1b; $* p<.05, * * p<.01$.

Table 2.

Means and inferential statistics for all measures in Study la.

\begin{tabular}{|c|c|c|c|c|c|}
\hline Dependent Variable & $\begin{array}{c}\text { Control Condition } \\
M(S D)\end{array}$ & $\begin{array}{c}\text { Awe Condition } \\
M(S D)\end{array}$ & $t$ & $p$ & $d$ \\
\hline Awe & $2.29(1.30)$ & $3.72(1.06)$ & 11.56 & $<.001$ & 1.21 \\
\hline Contentment & $3.28(1.13)$ & $3.56(1.08)$ & 2.38 & .018 & .25 \\
\hline Excitement & $2.67(1.20)$ & $3.10(1.24)$ & 3.25 & .001 & .35 \\
\hline Fear & $1.13(0.45)$ & $1.29(0.76)$ & 2.44 & .015 & .26 \\
\hline Joy & $3.27(1.29)$ & $3.45(1.19)$ & 1.41 & .159 & .15 \\
\hline Love & $2.89(1.35)$ & $3.25(1.25)$ & 2.65 & .008 & .28 \\
\hline Pride & $2.14(1.19)$ & $3.13(1.30)$ & 7.60 & $<.001$ & .79 \\
\hline Sadness & $1.28(0.72)$ & $1.36(0.70)$ & 1.08 & .279 & .11 \\
\hline Uncertainty & $1.44(0.82)$ & $1.55(0.91)$ & 1.21 & .229 & .01 \\
\hline Science interest & $5.24(1.09)$ & $5.47(1.11)$ & 1.97 & .050 & .21 \\
\hline Knowledge gaps & $4.81(1.28)$ & $5.19(1.19)$ & 2.95 & .003 & .31 \\
\hline Belief in science & $4.72(1.39)$ & $4.86(1.35)$ & .95 & .341 & .10 \\
\hline Need for cognition & $4.42(1.12)$ & $4.69(1.11)$ & 2.31 & .022 & .24 \\
\hline 7-tem CRT & $2.77(2.25)$ & $2.74(2.22)$ & .12 & .907 & .01 \\
\hline Religiosity & $3.46(2.11)$ & $3.60(2.25)$ & .58 & .561 & .06 \\
\hline
\end{tabular}




Spirituality $\quad 4.61(1.55) \quad 4.60(1.53)$

Note: Comparisons were made using an independent samples t-test.

Confirmatory analyses. To examine the pre-registered hypotheses, a series of t-tests were conducted. These indicated those in the awe condition reported greater science interest and greater awareness of knowledge gaps (see Table 2).

Next, a mediation analysis was conducted using PROCESS (Hayes, 2017) model 4 with 5,000 bootstrapped samples. Condition was entered as the independent variable, knowledge gaps as the mediator, and science interest as the dependent variable. The indirect effect from awe condition to awareness of knowledge gaps, to science interest was significant, $\beta=.16,95 \% \mathrm{CI}$ : $.0541, .2702$ (see Figure 1). These effects should not be interpreted as causal, but rather as a convenient way to depict the theoretically derived association between awe, knowledge gaps, and science interest.

Exploratory analyses. Exploratory tests examined whether the pattern of results held while controlling for positive (sans awe, $\alpha=.81)$ and negative $(\alpha=.87)$ emotion composites in a regression analysis. Science interest was first analyzed as an outcome. Condition $(\beta=.03, p=$ $.572)$ and awe $(\beta=.07, p=.390)$ were no longer significant predictors. Positive emotions $(\beta=$ $.22, p=.002)$ and negative emotions were $(\beta=.21, p<.001)$. Turning to knowledge gap awareness, condition $(\beta=-.013, p=.917)$ was not a significant predictor while controlling for the other variables. Awe remained a significant predictor $(\beta=.16, p=.034)$ as did positive emotions $(\beta=.35, p<.001)$; the negative emotions variable was not significantly related $(\beta=$ $.02, p=.654)$

However, these analyses are difficult to interpret because the condition variable is also strongly associated with awe and somewhat associated with the other positive and negative emotion variables. This complication means it is difficult to understand exactly what each 
variable is accounting for in this analysis. As such, it may be best to refrain from interpreting this as showing that one single variable is unambiguously associated with science interest or knowledge gaps. Additional exploratory analyses describing personality-level moderators are presented in the supplementary materials. In short, the relationship between awe condition and science interest was not moderated by any of these personality-level variables.

\section{Study 1b}

Manipulation check. Zero-order correlations are displayed in the bottom half of Table 1. A manipulation check again indicated the awe manipulation was successful: awe was greater in the awe condition compared to the control condition. Two other emotions (pride and sadness) differed between the two conditions, but these were again much smaller in magnitude (see Table 3).

Table 3.

Means and inferential statistics for all measures in Study $1 \mathrm{~b}$.

\begin{tabular}{|c|c|c|c|c|c|}
\hline Dependent Variable & $\begin{array}{l}\text { Control } \\
M \quad(S D)\end{array}$ & $\begin{array}{c}\text { Awe } \\
M(S D)\end{array}$ & $t$ & $p$ & $d$ \\
\hline Awe & $2.19(0.97)$ & $3.68(0.86)$ & 7.87 & $<.001$ & 1.63 \\
\hline Contentment & $3.28(1.36)$ & $3.72(0.93)$ & 1.86 & .066 & .37 \\
\hline Depressed & $1.17(0.43)$ & $1.20(0.45)$ & .28 & .783 & .07 \\
\hline Excitement & $2.74(1.14)$ & $2.98(1.01)$ & 1.07 & .287 & .22 \\
\hline Fear & $1.07(0.25)$ & $1.13(0.34)$ & 1.01 & .314 & .20 \\
\hline Lonely & $1.23(0.56)$ & $1.28(0.65)$ & .34 & .734 & .08 \\
\hline Love & $2.41(1.27)$ & $2.94(1.31)$ & 1.95 & .054 & .41 \\
\hline Pride & $1.85(1.08)$ & $2.60(1.12)$ & 3.27 & .002 & .68 \\
\hline Sadness & $1.15(0.42)$ & $1.53(0.93)$ & 2.58 & .011 & .53 \\
\hline Uncertainty & $1.66(0.89)$ & $1.53(0.83)$ & .72 & .474 & .15 \\
\hline Science Museum Tickets & $59 \%$ & $68 \%$ & .74 & .391 & .19 \\
\hline Science Interest & $4.75(1.14)$ & $5.16(1.04)$ & 1.85 & .069 & .38 \\
\hline Knowledge Gaps & $4.52(1.20)$ & $4.96(0.99)$ & 1.95 & .054 & .40 \\
\hline
\end{tabular}




\begin{tabular}{lllccc} 
Belief in Science & $4.52(1.18)$ & $4.17(0.95)$ & 1.60 & .114 & .32 \\
Need for Cognition & $4.62(0.94)$ & $4.56(0.74)$ & .35 & .724 & .07 \\
7-item CRT & $3.77(2.31)$ & $3.49(2.24)$ & .59 & .558 & .12 \\
Religiosity & $2.63(1.79)$ & $3.73(2.11)$ & 2.71 & .008 & .56 \\
Spirituality & $4.08(1.23)$ & $4.74(1.13)$ & 2.71 & .008 & .56 \\
\hline
\end{tabular}

Note: Comparisons were made using an independent samples t-test; comparisons for science museum tickets were conducted with a chi-square test.

Confirmatory analyses. T-tests indicated those in the awe condition reported somewhat greater science interest and awareness of knowledge gaps, though this was not conventionally significant. It is important to note that the effect sizes observed here are of the same magnitude of those observed in Study 1a, but the probability value may be lower due to sample size constraints.

As in Study 1a, a mediation analysis was conducted. Again, these effects should not be interpreted as causal, but rather as a convenient way to depict the theoretically derived association between awe, knowledge gaps, and science interest. The indirect effect from awe condition to awareness of knowledge gap, to science interest was again significant, $\beta=.17,95 \%$ CI: .0057, .3723. In a second model using logistic procedures, the indirect effect from condition, to awareness of knowledge gap, to choice of science museum ticket was significant, $\beta=.34$, 95\% CI: .0134, .9621. Though the total effect from condition to ticket choice was not significant $(\beta=.37, p=.391)$, it was of similar magnitude as the total effect of condition on science interest $(\beta=.38, p=.069)$. These effects are depicted in Figure 1.

Exploratory analyses. Exploratory tests examined whether the pattern of results held while controlling for positive $(\alpha=.75)$ and negative $(\alpha=.53)$ emotion composites in a regression analysis. Science interest was first analyzed as an outcome. Condition $(\beta=.14, p=.281)$ and awe $(\beta=-.08, p=.653)$ were no longer significant predictors. Positive emotions was 
significantly related to science interest $(\beta=.30, p<.001)$ but negative emotions was not $(\beta=$ $.08, p=.444)$.

Turning to knowledge gap awareness, condition $(\beta=-.05, p=.715)$, positive emotions $(\beta$ $=.05, p=.731)$, and negative emotions $(\beta=.10, p=.310)$ were not significantly related; only awe $(\beta=.35, p=.031)$ remained significant. While this replicates the finding from Study 1a, these analyses should also be interpreted carefully because the variance associated with condition overlaps significantly with the variance associated with the emotion outcomes. Additional exploratory analyses describing personality-level moderators are presented in the supplementary materials.

\section{Study 1c}

Manipulation check. A manipulation check again indicated the awe manipulation was successful: awe was greater in the awe condition compared to the control condition. Seven of the nine other emotions also differed between conditions (see Table 4): uncertainty and joy did not differ. Surprise was greater in the control condition while the other positive and negative emotions were greater in the awe condition.

Table 4. Means and inferential statistics for all measures in Study 1c.

\begin{tabular}{|c|c|c|c|c|c|}
\hline Dependent Variable & $\begin{array}{l}\text { Control } \\
M \quad(S D)\end{array}$ & $\begin{array}{c}\text { Awe } \\
M(S D)\end{array}$ & $t$ & $p$ & $d$ \\
\hline Awe & $2.06(1.11)$ & $3.61(1.05)$ & 20.98 & $<.001$ & 1.44 \\
\hline Contentment & $3.08(1.12)$ & $3.38(1.03)$ & 4.05 & $<.001$ & .28 \\
\hline Excitement & $2.35(1.17)$ & $2.93(1.18)$ & 7.13 & $<.001$ & .49 \\
\hline Fear & $1.08(.39)$ & $1.22(.57)$ & 4.20 & $<.001$ & .29 \\
\hline Joy & $3.15(1.25)$ & $3.17(1.14)$ & .26 & .795 & .02 \\
\hline Love & $2.55(1.21)$ & $2.82(1.25)$ & 3.19 & .001 & .22 \\
\hline Pride & $1.85(1.06)$ & $2.59(1.27)$ & 9.19 & $<.001$ & .63 \\
\hline
\end{tabular}




\begin{tabular}{lccccc} 
Sadness & $1.22(.58)$ & $1.44(.77)$ & 4.82 & $<.001$ & .32 \\
Surprise & $2.12(1.12)$ & $1.89(1.08)$ & 3.00 & .003 & .21 \\
Uncertainty & $1.52(.85)$ & $1.60(.86)$ & 1.33 & .184 & .09 \\
Knowledge gaps & $4.71(1.26)$ & $5.10(1.20)$ & 4.65 & $<.001$ & .32 \\
Science interest & $5.30(.98)$ & $5.49(.93)$ & 2.91 & .002 & .20 \\
\hline
\end{tabular}

Note: Comparisons for emotions were made using a two-tailed independent samples t-test; onetailed t-tests were used for knowledge gaps and science interest.

Confirmatory analyses. One sample t-tests were used to test the primary hypotheses. As shown in Table 4, those in the awe condition reported greater science interest and greater awareness of knowledge gaps. A mediation analysis using PROCESS replicated the effects from studies $1 \mathrm{a}$ and $1 \mathrm{~b}$ : the indirect effect from condition to knowledge gaps to awe was significant: $\beta$ $=.14,95 \%$ CI: $.0791, .2101$. These effects should not be interpreted as causal, but rather as a convenient way to depict the theoretically derived association between awe, knowledge gaps, and science interest.

Exploratory analyses. Exploratory analyses again examined whether the pattern of results held while controlling for positive $(\alpha=.88)$ and negative $(\alpha=.62)$ emotion composites in a regression analysis. Science interest was first examined as an outcome. Condition $(\beta=.07, p=$ $.116)$ and awe $(\beta<-.01, p=.988)$ were no longer significant predictors of science interest. Positive emotions was significantly related to science interest $(\beta=.25, p<.001)$ but negative emotions was not $(\beta=-.05, p=.174)$. Turning to knowledge gap awareness, condition $(\beta<-.01$, $p=.928)$ was not a significant predictor. However, awe $(\beta=.16, p=.002)$ was a significant predictor alongside positive $(\beta=.35, p<.001)$ and negative emotions $(\beta=.09, p=.004)$. As with Studies 1a and 1b, these analyses should be considered carefully.

\section{Discussion}


These studies provide the first evidence that awe influences an awareness of gaps in one's knowledge: the experience of awe consistently and uniquely led to increases in awareness of gaps in one's knowledge about the natural world. Additionally, the experimental video led to slight increases in science interest. These key results are summarized in Table 5, below.

Table 5.

Summary of key results and effect sizes across all studies.

\begin{tabular}{|c|c|c|c|c|c|c|c|c|c|c|}
\hline \multirow[b]{3}{*}{ Variable } & \multicolumn{5}{|c|}{ Study 1a } & \multicolumn{5}{|c|}{ Study $1 \mathrm{~b}$} \\
\hline & $\begin{array}{l}\text { Control } \\
(n=185)\end{array}$ & $\begin{array}{c}\text { Awe } \\
(n=181)\end{array}$ & & & & $\begin{array}{l}\text { Control } \\
(n=47)\end{array}$ & $\begin{array}{c}\text { Awe } \\
(n=47)\end{array}$ & & & \\
\hline & $M(S D)$ & $M(S D)$ & $t$ & $p$ & $d$ & $M(S D)$ & $M(S D)$ & $t$ & $p$ & $d$ \\
\hline \multirow{5}{*}{$\begin{array}{l}\text { Awe } \\
\text { Knowledge } \\
\text { gaps } \\
\text { Science } \\
\text { interest }\end{array}$} & $2.29(1.30)$ & $3.72(1.06)$ & 11.56 & $<.001$ & 1.21 & $2.19(0.97)$ & $3.68(0.86)$ & 7.87 & $<.001$ & 1.63 \\
\hline & $4.81(1.28)$ & $5.19(1.19)$ & 2.95 & .003 & .31 & $4.52(1.20)$ & $4.96(0.99)$ & 1.95 & .054 & .40 \\
\hline & $5.24(1.09)$ & $5.47(1.11)$ & 1.97 & .050 & .21 & $4.75(1.14)$ & $5.16(1.04)$ & 1.85 & .069 & .38 \\
\hline & \multicolumn{5}{|c|}{ Study 1c } & & & & & \\
\hline & $\begin{array}{l}\text { Control } \\
(n=418)\end{array}$ & $\begin{array}{c}\text { Awe } \\
(n=432)\end{array}$ & & & & & & & & \\
\hline \multirow{4}{*}{\begin{tabular}{l}
\multicolumn{1}{c}{ Variable } \\
Awe \\
Knowledge \\
gaps \\
Science \\
interest
\end{tabular}} & $M(S D)$ & $M(S D)$ & $t$ & $p$ & $d$ & & & & & \\
\hline & $2.06(1.11)$ & $3.61(1.05)$ & 20.98 & $<.001$ & 1.44 & & & & & \\
\hline & $4.71(1.26)$ & $5.10(1.20)$ & 4.65 & $<.001$ & .32 & & & & & \\
\hline & $5.30(.98)$ & $5.49(.93)$ & 2.91 & .002 & .20 & & & & & \\
\hline \multicolumn{11}{|c|}{ Study 2} \\
\hline & $\begin{array}{l}\text { Control } \\
(n=53)\end{array}$ & $\begin{array}{c}\text { Awe } \\
(n=54)\end{array}$ & \multicolumn{3}{|c|}{ Planned contrast \#1 } & $\begin{array}{c}\text { Awe + } \\
\text { relevant } \\
(n=49)\end{array}$ & $\begin{array}{c}\text { Awe + irrelevant } \\
(n=53)\end{array}$ & \multicolumn{3}{|c|}{ Planned contrast \#3 } \\
\hline Variable & $M(S D)$ & $M(S D)$ & $t$ & $p$ & $d$ & $M(S D)$ & $M(S D)$ & $t$ & $p$ & $d$ \\
\hline \multirow{3}{*}{$\begin{array}{l}\text { Awe } \\
\text { Knowledge } \\
\text { gaps } \\
\text { Science } \\
\text { interest }\end{array}$} & $3.71(1.86)$ & $5.61(1.20)$ & 5.98 & $<.001$ & 1.22 & $4.75(1.57)$ & $3.83(1.82)$ & 2.83 & .005 & .54 \\
\hline & $4.81(1.08)$ & $5.31(.91)$ & 2.73 & .007 & .50 & $5.20(.84)$ & $5.09(.96)$ & 1.48 & .140 & .21 \\
\hline & $4.84(1.00)$ & $5.10(1.05)$ & 1.06 & 1.81 & .27 & $4.71(.99)$ & $5.09(1.06)$ & 1.83 & .068 & .37 \\
\hline
\end{tabular}

Note: For studies 1a and 1b, means were compared using an independent samples t-test; for Study 2, means were compared using a series of a priori planned comparisons.

Figure 1. 
Summary of the indirect effects from awe condition to science interest and choice of museum tickets through awareness of knowledge gaps across all studies.

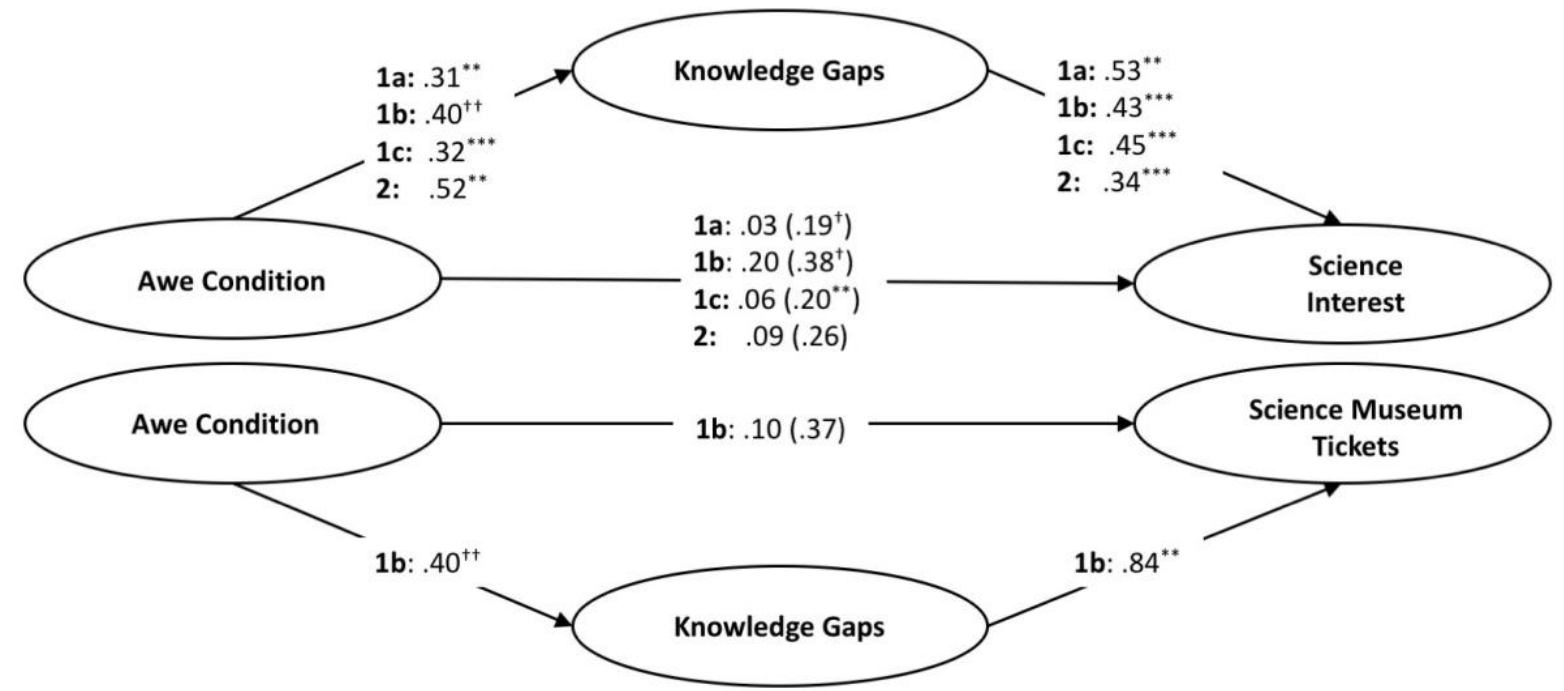

Note: Mediation model depicting the indirect effects across all four studies. In all studies, exposure to the awe condition $(0=$ control and $1=$ awe $)$ led to an increase in awareness of knowledge gaps, which in turn was associated with an increased level of science interest and, in Study $1 b$, to an increased likelihood of choosing tickets to a science museum $(0=$ art museum, 1 $=$ science museum). Standardized coefficients are shown; coefficients outside parentheses are after including the mediator in the model; ${ }^{\dagger} p<.07,{ }^{\dagger \dagger} p=.054 * p<.05, * * p<.01, * * * p<.001$.

Exploratory analyses indicate that the experimental manipulation did not consistently influence any other outcome measures, nor were the effects of condition moderated by any of these other measures (see supplementary materials). However, these exploratory analyses also showed that science interest was better predicted by the positive emotions composite.

Additionally, in Studies 1a and 1c, both awe and positive emotions were significantly related to knowledge gaps. Further, the experimental manipulation consistently influenced other emotional states. These results are quite consistent and suggest that awe was indeed experienced as a positive emotion. Although the preregistered analyses are consistent with the theoretical model, the exploratory results also lend to the possibility that awe has the effects it does because it is a positive emotion. 
At the same time, though, it remains unclear exactly what the condition variable is responsible for eliciting. In exploratory analyses for each study, the condition variable was entered simultaneously alongside awe, positive affect, and negative affect. Indeed, the experimental condition was responsible for changes in various other emotions, so including these four variables simultaneously makes it difficult to interpret the unique effects of each on science interest and knowledge gaps. Clearly, future researchers will need to develop more specific manipulations of awe (and other various emotions) if the effects of interest are to be studied more precisely.

Unfortunately, these data do not allow one to disentangle awe from other positive emotions. Given the ambiguity of awe as it related to science interest, the pattern of results observed here leads to two additional possible interpretations of the data. First is that participants may simply be unable to distinguish between different emotions in a self-report format. Second, is that the effects observed on science interest may be partially due to positive affect rather than awe alone. These additional emotion items were included as distractors from the awe measure, so these analyses are exploratory and were not planned, though they are consistent and offer additional information about the role of awe.

\section{Study 2}

Studies 1a-1c showed that the experience of awe promotes awareness of gaps in one's knowledge about the natural world. The goal of study 2 was then to 1) replicate these effects using a different procedure to induce awe, and 2) to test whether the awareness of knowledge gaps and science interest can be "satisfied" by providing information about the awe-inducing event - that is, by promoting accommodation of this information into their existing schemas (Keltner \& Haidt, 2003). 
This prediction is based on theorizing by Keltner and Haidt (2003) that the experience of awe promotes the need for accommodation. That is, providing information directly after the stimulus may assist participants in accommodating information about the experience. However, it may also be that the knowledge gaps and science interest simply diminish over time or after receiving any information, whether relevant to the awe-inducing experience or not. Participants were therefore randomized into two conditions where they receive information either relevant or irrelevant to the awe-inducing stimuli.

Additionally, the goal was also to conceptually replicate Studies 1a and 1b using a different technique to elicit awe: virtual reality videos. Past research has shown that virtual reality videos are strong and reliable inducers of awe (Chirico, Cipresso, Yaden, Biassoni, Riva, \& Gaggioli, 2017; Chirico, Ferrise, Cordella, \& Gaggioli, 2018). To replicate Studies 1a-1c, it was predicted that, after being exposed to a virtual reality video, participants would report increased awe, science interest, and awareness of knowledge gaps, and that awareness of knowledge gaps would again be related to (e.g. mediate) increase in science interest. The procedures, hypotheses, analyses, and sample size were pre-registered with the Open Science Framework prior to data collection (https://osf.io/3ymf5/?view_only=5e5e8a5b60eb424394672953fbfb192d).

\section{Participants}

Because Study 2 contains four conditions, a power analysis using the same criteria as above indicates that this would require a sample size of 704, which is larger than the available subject pool. As noted in the pre-registration form, 212 undergraduates were recruited to maintain a manageable sample size but still recruit at least 50 per cell. There were 169 females 
and 42 males ( 1 did not identify) with an average age of $20.25(S D=1.43)$. Three participants who had problems with the headset were excluded, resulting in a final sample of 209.

\section{Materials and Procedure}

Participants arrived in the laboratory individually and were randomly assigned to one of four conditions: 1) awe, 2) control, 3) awe + relevant information, and 4) awe + irrelevant information. These four conditions allowed testing of two predictions. First, that awe (vs. control) would lead to greater awareness of knowledge gaps and science interest. Second, that providing relevant information (vs. irrelevant information) about the awe inducing event would satisfy (i.e., diminish) the knowledge gaps and interest to the level observed in the control condition.

In the awe condition, participants watched a $3 \mathrm{D}, 360^{\circ} \mathrm{VR}$ video of the aurora borealis, which was displayed on a Samsung Gear VR headset powered by a Samsung Galaxy S6 and headphones. In the control condition, participants watched the same video as in Study 1 (BBC's Walk on the Wild Side) using the VR headset, but the video was displayed in $2 \mathrm{~d}$ format. Following the video, participants reported on 10 emotions and completed the same self-report measures, in the same order, as used in Studies 1a. These two conditions allowed testing of the first hypothesis.

In the second two conditions, which allowed testing of the second hypothesis, participants first watched the same awe-inducing VR video in 3D. However, this was followed by another video either explaining the aurora borealis (awe + relevant information) or a video explaining how to tie different knots (awe + irrelevant information). Comparisons between the awe + irrelevant information and the awe + relevant information conditions could show whether 
the awe-induced knowledge gap dissipates after receiving any information or whether information specific to the awe-inducing stimuli is needed.

The informational aurora video is understandable to a general audience and teaches people about the science behind the auroras and when it occurs. It is freely available and was created by a science outreach Youtube channel (Sci-show: https://youtu.be/nXxwZVbDt1c). The irrelevant video simply explained how to tie a few different knots and what the knots can be used for; this video was chosen because it is informative, but unrelated to science or to the aurora. These two videos were embedded in the Qualtrics survey on a computer (i.e., not in VR). Participants then reported on emotions and responded to all outcome measures as above, in the same order. Finally, participants completed demographics information.

\section{Results}

Zero-order correlations are displayed in Table 6. A manipulation check was conducted to compare self-reported awe between the four conditions with a one-way $\operatorname{ANOVA,~} F(3,205)=$ 15.71, $p<.001, \eta^{2} \mathrm{p}=.19$. Dunnett's post-hoc comparisons indicate those in the awe condition reported higher levels of awe compared to the control condition, $p<.001, d=1.22$. Only awe and pride were significantly greater in the awe (versus the control) condition; again, the difference for pride is much smaller than the difference for awe. Additionally, joy and happiness were higher in the awe + irrelevant condition than in the other three conditions. Overall, those in the awe + irrelevant conditions experienced less positive emotions compared to the other three conditions.

Table 6.

Zero-order correlations between all variables in Study 2.

\begin{tabular}{lllllll}
\hline & 2 & 3 & 4 & 5 & 6 & 7 \\
\hline
\end{tabular}

1. Awe

2. Science Interest 


\begin{tabular}{lrrrrrrrr} 
3. Knowledge Gaps & $.24^{* *}$ & $.34^{* *}$ & & & & & \\
4. Belief in Science & -.03 & $.23^{\star *}$ & -.01 & & & & \\
5. Need for Cognition & -.10 & $.36^{* *}$ & .06 & -.04 & & & \\
6. CRT & -.08 & .09 & .05 & $.14^{*}$ & $.25^{* *}$ & & \\
7. Religiosity & .01 & -.09 & .02 & $-.42^{* *}$ & .04 & $-.21^{* *}$ & \\
8. Spirituality & .10 & .09 & $.17^{*}$ & $-.23^{* *}$ & -.03 & $-.16^{*}$ & $.46^{* *}$ \\
\hline Note. $* p<.05, * * p<.01$ & & & & & & &
\end{tabular}

Note: $* p<.05, * * p<.01$.

\section{Confirmatory Analyses}

Science interest. Following the preregistered analysis plans, the main hypotheses were examined using three a priori planned contrasts. Means and effect sizes for all measures by condition are displayed in Table 7. To test whether awe resulted in increased science interest, the first contrast compared the awe condition to the control condition; the other two conditions were coded with a weight of 0 . Results showed science interest was not significantly different between the awe and control conditions, $t(202)=1.06, p=.181, d=.27$. However, the effect size was again of similar magnitude as those reported in studies $1 \mathrm{a}$ and $1 \mathrm{~b}(d s=.21, .38$, respectively). Indeed, a sensitivity analysis (Faul, et al., 2007) indicates that this analysis lacks the power to detect an effect of this size.

Table 7.

Means by condition for all outcome variables in Study 2.

\begin{tabular}{lcccc}
\hline Dependent Variable & Control & Awe & Awe + Relevant & Awe + Irrelevant \\
& $M(S D)$ & $M(S D)$ & $M(S D)$ & $M(S D)$ \\
\hline Awe & $3.71(1.86)_{\mathrm{a}}$ & $5.61(1.2)_{\mathrm{b}}$ & $4.75(1.57)_{\mathrm{b}}$ & $3.83(1.82)_{\mathrm{a}}$ \\
Contentment & $5.02(1.65)_{\mathrm{a}, \mathrm{b}}$ & $5.43(1.16)_{\mathrm{a}}$ & $5.06(1.2)_{\mathrm{a}, \mathrm{b}}$ & $4.38(1.43)_{\mathrm{b}}$ \\
Happy & $5.43(1.31)_{\mathrm{a}}$ & $5.30(1.14)_{\mathrm{a}}$ & $5.04(1.17)_{\mathrm{a}}$ & $4.30(1.23)_{\mathrm{b}}$ \\
Fear & $1.37(1.07)_{\mathrm{a}}$ & $1.57(.94)_{\mathrm{a}}$ & $1.45(.84)_{\mathrm{a}}$ & $1.11(.38)_{\mathrm{b}}$ \\
Joy & $5.11(1.41)_{\mathrm{a}}$ & $4.56(1.37)_{\mathrm{a}}$ & $4.61(1.34)_{\mathrm{a}}$ & $3.40(1.59)_{\mathrm{b}}$
\end{tabular}




\begin{tabular}{lcccc} 
Love & $3.43(1.65)_{\mathrm{a}}$ & $3.65(1.95)_{\mathrm{a}}$ & $3.67(1.63)_{\mathrm{a}}$ & $2.32(1.49)_{\mathrm{b}}$ \\
Pride & $2.25(1.37)_{\mathrm{a}}$ & $3.17(1.81)_{\mathrm{b}}$ & $2.90(1.64)_{\mathrm{a}, \mathrm{b}}$ & $2.30(1.56)_{\mathrm{a}}$ \\
Sadness & $1.19(.45)_{\mathrm{a}}$ & $1.59(1.04)_{\mathrm{a}}$ & $1.59(.89)_{\mathrm{a}}$ & $1.43(.91)_{\mathrm{a}}$ \\
Surprise & $3.60(1.82)_{\mathrm{a}} \mathrm{b}$ & $3.85(2.01)_{\mathrm{a}}$ & $3.67(1.89)_{\mathrm{a}, \mathrm{b}}$ & $2.75(1.93)_{\mathrm{b}}$ \\
Uncertainty & $2.40(1.73)_{\mathrm{a}}$ & $2.48(1.71)_{\mathrm{a}}$ & $2.49(1.47)_{\mathrm{a}}$ & $2.36(1.56)_{\mathrm{a}}$ \\
\hline Science Curiosity & $4.84(1.00)_{\mathrm{a}}$ & $5.10(1.05)_{\mathrm{a}}$ & $4.71(.99)$ & $5.09(1.06)$ \\
Knowledge Gaps & $4.81(1.08)_{\mathrm{a}}$ & $5.31(.91)_{\mathrm{b}}$ & $5.20(.84)$ & $5.09(.96)$ \\
Belief in Science & $4.36(1.07)_{\mathrm{a}}$ & $4.24(1.00)_{\mathrm{a}}$ & $4.31(1.19)$ & $4.55(.96)$ \\
Need for Cognition & $4.67(.79)_{\mathrm{a}}$ & $4.72(.70)_{\mathrm{a}}$ & $4.48(.80)$ & $4.80(.82)$ \\
7-item CRT & $3.30(2.14)_{\mathrm{a}}$ & $3.70(2.11)_{\mathrm{a}}$ & $3.65(2.26)$ & $4.47(2.04)$ \\
Religiosity & $3.48(1.98)_{\mathrm{a}}$ & $3.17(1.76)_{\mathrm{a}}$ & $3.36(1.83)$ & $3.29(1.71)$ \\
Spirituality & $4.62(1.07)_{\mathrm{a}}$ & $4.56(1.19)_{\mathrm{a}}$ & $4.47(1.08)$ & $4.65(1.11)$ \\
\hline
\end{tabular}

Note: Means by condition were compared using a priori planned contrasts; measures in the

bottom half of the table were compared using a planned contrast between the control and awe condition to mirror the analyses from studies $1 \mathrm{a}$ and $1 \mathrm{~b}$.

The second planned contrast compared the two unsatisfied awe conditions (awe and awe + irrelevant information) to the other two conditions (control and awe + relevant information). This analysis examined whether providing information relevant to the awe-inducing stimuli would reduce science interest to the level of the control condition, whereas science interest would remain higher in the two conditions where awe remained unsatisfied (the awe and awe + irrelevant conditions). This test also has the benefit of increased statistical power given the limited sample size. The test indicated this was the case, as those in the unsatisfied awe conditions reported greater science interest, $t(205)=2.25, p=.026, d=.32$.

The third planned contrast compared only the awe + relevant information and awe + irrelevant information conditions and tests whether providing relevant (versus irrelevant) information will reduce science interest. This test indicated a somewhat greater level of science 
interest in the awe + irrelevant information condition, $t(205)=1.83, p=.068, d=.37$. Thus, providing relevant information about the aurora somewhat decreased self-reported interest in science compared to when participants received irrelevant information about tying knots.

Knowledge gaps. Replicating the effects from Studies 1a and 1b, the first planned contrast indicates that those in the awe condition reported greater awareness of knowledge gaps compared to those in the control condition, $t(205)=2.73, p=.007, d=.50$.

The second and third contrasts were not significant, $t(205)=1.48, p=.140, d=.21$, and $t(205)=.60, p=.552, d=.12$, respectively. This suggests that providing information about the awe-inducing experience does not satisfy knowledge gaps; rather the knowledge gap persists even after obtaining further information, regardless of whether this information was relevant or not.

Mediation analysis. A mediation analysis was then conducted to investigate whether awareness of knowledge gaps accounts for additional variance in science interest. Condition was entered in as the independent variable, knowledge gaps as the mediator, and science interest as the dependent variable. The first analysis compared only the awe and control conditions to be consistent with Studies 1a and 1b. The indirect effect from the awe condition to knowledge gaps to science interest was significant, $\beta=.18,95 \%$ CI: .0382, .3107 (see Figure 1).

The second analysis compared the awe + relevant to the awe + irrelevant condition, but this was not significant, $\beta=-.04,95 \% \mathrm{CI}:-.1949, .1050$ (see supplementary materials). Thus, to the extent one is still aware of these knowledge gaps, they report greater levels of interest in science. However, providing relevant information about the awe-inducing event does not decrease the awareness of knowledge gaps.

\section{Exploratory Analyses}


Exploratory analyses were also conducted to examine whether the pattern of results held while controlling for positive $(\alpha=.80)$ and negative $(\alpha=.55)$ emotion composites. Additional exploratory analyses investigating personality-level moderators are described in the supplementary materials.

Here, only the awe and control conditions were included to mirror the analyses conducted in the previous two studies. Looking at awareness of knowledge gaps, effects of condition $(\beta=$ $.09, p=.394)$, awe $(\beta=.19, p=.147)$, positive $(\beta=.20, p=.144)$ and negative $(\beta=.05, p=$ .604) emotions were all non-significant.

Looking at science interest, only condition $(\beta=.23, p=.038)$ and awe $(\beta=.27, p=.042)$ were positively related to science interest while controlling for other emotions. Positive ( $\beta=-$ $.08, p=.578)$ and negative emotions $(\beta=.01, p=.906)$ were not related to science interest.

\section{Discussion}

These results largely replicate the effects found in Studies 1a and 1b. First, the experience of awe led to greater awareness of knowledge gaps compared to a control condition. Second, the experience of awe led to greater science curiosity; though these effects were not statistically significant, the effect size was of similar magnitude as in the previous two studies.

However, exploratory analyses contradicted those observed in Studies 1a-c. Controlling for positive and negative emotions wiped out the relation between awe, condition, and knowledge gaps. Conversely, only condition and awe were related to science interested while controlling for positive and negative emotions. This again highlights the need for more specific and precise manipulations of awe because these analyses highlight ambiguous associations between the condition variable and various emotional outcomes. 
Importantly, Study 2 does show that the awareness of knowledge gaps is not simply diminished by teaching people about the awe-inducing stimuli just encountered. This could be interpreted as consistent with the conceptualization of awe as an epistemic emotion (Keltner \& Haidt, 2003) — that is, simply learning about a specific stimulus does not necessarily constitute an epistemology. In this case, it could be argued that information about the aurora may satisfy curiosity or wonder about the aurora without calling upon the larger epistemological system of knowledge represented by science (or religion). Thus, further research will be needed to explore whether these broader knowledge gaps can be satisfied, but this is a question much larger than the scope of the present studies.

One limitation to be considered here is that the awe-inducing stimuli was presented on a VR headset in 3D mode while the control video was presented in 2D mode. This was done to control for the "wow factor" in experiencing new technology. However past research (Chirico et al., 2017, 2018) suggests that VR technology augments the experience of awe above the content of media. This means it is impossible to say whether the content or the medium is responsible for the effects of condition on the emotional responses. A second limitation is that the informational and non-informational videos used here were not matched on other criteria. It is then possible that other factors and characteristics which were not measured here are responsible for the effects measured. For example, the knots or aurora videos may have some other characteristic which is responsible for increasing or decreasing knowledge gaps. Of course, the answer to these questions are outside of the scope of the study, but these limitations should be kept in mind when interpreting these results.

\section{Meta-Analytic Summary}


Across the three studies, some of the effects varied in magnitude, so I thought it desirable to investigate the effects meta-analytically. Using Open Meta-analyst (Wallace et al., 2012), I computed a fixed-effects model using science interest and awareness of knowledge gaps as the outcomes across Studies 1a, 1b, 1c, and 2. For Study 2, I only included the comparisons between the awe and control conditions. I report meta-analytic effects of all other variables in the supplementary materials (see Table S6).

The awe condition resulted in greater awareness of knowledge gaps, Cohen's $d=-.41, p$ $<.001,95 \% \mathrm{CI}[-.530,-.280]$. The awe condition also led to greater science interest compared to the control condition, Cohen's $d=-.22, p<.001,95 \%$ CI [-.336, - .107]. The analysis also revealed a significant indirect effect from awe condition to awareness of knowledge gaps to science interest, est $\beta=.151, p<.001,95 \% \mathrm{CI}: .102, .201$.

\section{General Discussion}

The relatively simple stimuli used in the present studies — online videos and virtual reality videos_-led to greater awareness of gaps in one's knowledge consistently across four studies. Awareness of knowledge gaps, in turn, was associated with increased science interest and to a greater likelihood of choosing tickets to a science museum over tickets to an art museum. Importantly, the effects of awe were not consistently observed on, nor moderated by, any other measure related to cognition or religiosity (see supplementary materials). Finally, in Study 2, it was found that the effects of awe on knowledge gap awareness were not cancelled by simply providing information about the awe inducing event, but science interest was marginally decreased after receiving information relevant to the awe-inducing stimuli. This suggests that the experience of awe may be unique to knowledge and understanding of the natural world, an area that science is well-suited to explain. 
However, the experimental manipulation did consistently influence other emotions. Additionally, though awe was uniquely related to knowledge gaps alongside positive emotions, the positive emotions composite was a stronger predictor of knowledge gaps and science interest. Thus, the effect reported here cannot be unambiguously attributed to awe though they are theoretically consistent. The possibility remains that awe is experienced as a positive emotion and it is positive emotions which, when associated with science-related stimuli, increase awareness of knowledge gaps and interest in science.

\section{Theoretical Significance}

The present studies represent the first direct empirical tests of the conceptualization of awe as a "knowledge" or epistemic emotion. That is, the effects and functions of awe have been theorized but have not been empirically tested. Specifically, awe has been described as an epistemic emotion because it may be related to our knowledge and understanding of the world, may involve a need for accommodation and understanding, and may promote people to seek out

more information about the awe-inspiring event (Keltner \& Haidt, 2003). Further, Valdesolo and colleagues (2017) proposed that the experience of awe may be an important antecedent for science learning and interest in science. While previous research has shown that awe promotes “feeling small" (van Elk et al., 2016), prosocial behaviors (Piff et al., 2015) and feelings of connectedness (Van Cappellen \& Saroglou, 2012), none of these outcomes are directly tied to the conceptualization of awe as an epistemic emotion.

Awe as a knowledge emotion. These results support Keltner and Haidt's (2003) perspective of awe as being related to knowledge: the experience of awe consistently led people to report greater awareness of gaps in their knowledge; this effect was quite robust and consistent. Awareness of knowledge gaps, in turn, was consistently associated with interest in 
science. To the extent that participants were more aware of their knowledge gaps, they reported greater science interest and were more likely to choose tickets to the science museum over tickets to an art museum. Thus, the interpretation here is that, when in awe, people seek out some information about the world through science-possibly because science is well-suited to explain our natural world. However, this interpretation is derived from the pattern of associations presented in cross-sectional mediation models as predicted by previous theorizing (Valdesolo et al., 2017). While this is theoretically consistent, it does not rule out the possibility that awe influences knowledge and science interest because it is a positive emotion.

In Study 2, participants were provided with information relevant to the awe-inducing stimuli. This did not diminish their awareness of knowledge gaps, though it did marginally decrease science interest. Thus, it appears that providing relevant information did not move people to accommodate this information into their existing schemas about the world. There are several possible explanations for these results. First, awe is described as an epistemic emotion (Keltner \& Haidt, 2003; Valdesolo et al., 2017) because it is hypothesized to be related to larger systems of knowledge, such as those offered by science and religion. Simply teaching people about the science behind the auroras may not be enough to satisfy this type of knowledge gap. Indeed, theory and research has differentiated awe from other knowledge emotions like curiosity and wonder, based on reasoning that awe seems to be related to much more grandiose and magnificent experiences. Curiosity and wonder, on the other hand, may be much more limited in scope and magnitude. Thus, in Study 2, providing information about the aurora may have satisfied curiosity or wonder about the auroras, but is likely not sufficient to satiate the kind of grand questions about the universe arising from experiences of awe. Future research will need to test these possibilities. 
Additionally, it may be that learning more about the aurora borealis simply reinforced those knowledge gaps. That is, once made aware of gaps in one's knowledge, these gaps may persist indefinitely. Indeed, Dunning (2011) has described how one is often unaware of what one doesn't know - a similar effect may be happening here where one simply becomes aware of what is not known, and this effect does not dissipate.

Another possibility is that this result arises because the awareness of knowledge gaps questionnaire was not specific to the aurora borealis, but rather focused on a global awareness of knowledge about nature. Perhaps learning about a specific science topic did not diminish participants' awareness of general knowledge gaps, but this result may have been different had the questionnaire focused specifically on knowledge gaps about the aurora. Again, this may be more related to the conceptualization of curiosity or wonder.

Awe and science interest. The present results also provide some for support Valdesolo and colleagues (2017) hypothesis that awe leads to science interest. This effect of condition on science interest was small but consistent in magnitude across four studies (and the meta-analytic result is also significant). One reason this effect may be small is because the science interest measure used here is very general and not directly related to the content of the manipulation. That is, the video depicts general scenes of nature but the scale measures specific interests (e.g., the space program) and activities (e.g., viewing dinosaur bones).

More importantly, in Studies 1a-c, positive emotions were a stronger predictor of science interest than was the self-reported awe emotion. In Study 2, condition and awe were better predictors. This pattern of results yields additional interpretations. For example, awe may simply operate as a positive emotion. Alternatively, people may be unable to distinguish between positive emotions even if awe is unique. These data do not allow for distinguishing between awe 
and positive emotions, nor was that the goal of the study. Future research will be needed to answer this question.

Exploratory results. In the present studies, many additional outcomes and moderators were included for exploratory purposes (see supplementary materials). This was indeed tangential to the main purpose of the study and no preregistered hypotheses were proposed.

Cognitive style. The reason for investigating these additional measures as outcomes and as moderators was that individual differences in cognitive style or need for cognition have been shown to be related to interest in science. For example, some people may be less interested in science because of a more intuitive cognitive style (Gervais, 2015) or because they simply enjoy thinking less. Further, if awe is a "knowledge emotion" as theorists have described (Keltner \& Haidt, 2003; Valdesolo et al, 2017), then the experience of awe may simply influence any measure related to knowledge or cognition. However, the present results showed this was not the case. The effects of the experimental manipulation were limited to knowledge gaps and science interest and were not consistently observed on any other measure related to cognition. In Study 1a, need for cognition (Caccioppo \& Petty, 1982) was slightly higher in the awe condition, but this effect did not appear in either of the other two studies. Further, individual differences in need for cognition or cognitive style did not moderate the effects of awe on science interest. Finally, self-reported uncertainty did not differ between the two conditions in any of the three studies. Therefore, the effects of awe appear to be unique to the awareness of knowledge gaps and science interest scales, which focus on knowledge about the natural world.

Religiosity and spirituality. Measures of religiosity and spirituality were included as possible outcomes and moderators. Differences in religious and spiritual beliefs have been argued to be related to a preference for religious worldviews over scientific worldviews 
(McPhetres \& Nguyen, 2016), so the effects of awe may be different for individuals based on their belief systems. That is, a religious person may take an awe-inspiring experience and turn to their religion for understanding (Van Cappellen \& Saroglou, 2012); a non-religious person may turn to science, instead.

Conversely, other researchers have argued that religion and science are not incompatible (e.g., Banerjee \& Bloom, 2015; Evans, 2001; Evans \& Lane, 2011; Järnefelt, Canfield, \& Kelemen, 2015). In the present studies, no effects of awe were consistently observed on religiosity or spirituality. In Study 1b, self-reported religiosity and spirituality were greater in the awe condition, but these differences were not observed in the other two studies. This suggests that the experience of awe may be unique to knowledge and understanding of the natural world - an area that science is well-suited to explain — and are independent of individual differences in belief systems. Also adding support to this interpretation is that individual differences in religiosity did not moderate the effects of awe on science interest.

However, Valdesolo et al (2017) previously reported that awe decreased belief in science (Farias et al., 2015) for religious, but not for non-religious, people. Recall that the belief in science scale differs from science interest in that it pits a preference for science against a preference for religion. In the present studies, these effects were not replicated (see supplementary materials). There may be several reasons for this, including lower power than in the original studies, the placement of the religiosity scale after the manipulation, the randomization of the belief in science scale alongside other measures, or even idiosyncratic differences between samples. Thus, caution is urged in interpreting this result. However, this also lends to the present interpretation that the effects of awe are related uniquely to knowledge and 
interest in the natural sciences, presumably because science is best suited to explaining questions arising from the awe-inducing videos used in these studies.

\section{Limitations and Future Research}

A first limitation which requires some attention is that it remains unclear exactly what the condition variable is responsible for eliciting. Because the condition elicited changes in various other emotions, exploratory analyses following each study sought to examine whether the condition, awe, positive affect, or negative affect variables were the stronger unique predictors. However, these analyses are limited in their ability to answer this question because the variance associated with condition overlaps significantly with the emotion variables. Thus, these analyses render little additional interpretive information. Instead, this highlights the need for more specific and clear manipulations of awe if its effects are to be better studied.

A second limitation is that the mediation analyses should not be interpreted as evidence for causation (Trafimow, 2015). Instead, they represent a pattern of correlational results which happen to be consistent with the preregistered predictions and, to some extent, consistent with previous theorizing. For example, another interpretation of the mediation models depicted in Figure 1 is that knowledge gaps is the better predictor of science interest while controlling for the effects of condition.

Another limitation of the present studies is that the outcomes here are self-reported. Future research should focus on implementing behavioral outcomes related to knowledge, learning, and science interest. For example, objective measures of learning may help clarify the role of knowledge gaps. It also remains to be seen whether a more general measure of knowledge gaps would produce the same result or if one is only aware of knowledge gaps that are directly related to the awe stimuli. Further, it remains to be seen whether one would report greater 
interest in other topics. For example, one may simply report being more interested in any topic, in line with Fredrickson's (2013) hypothesized broaden-and-build function of positive emotions, though such a possibility is not necessarily contrary to the hypothesized function of awe. Alternatively, it may be that awe only promotes interest in topics specifically related to the stimuli (e.g., auroras) or more broadly related to the stimuli (e.g., any natural science topics). More research will be needed to understand the boundary conditions of awe.

One other aspect that may be seen as a limitation is that the experimental manipulation influenced other emotions. Several emotions differed between the experimental and control conditions in Study 1a, only pride and sadness differed in Study 1b, and only pride in Study 2. Thus, the manipulation is not necessarily specific to awe. Again, it remains unclear exactly what the experimental condition is responsible for manipulating given that other emotions were also affected.

One may argue that the effects of science interest observed here are simply a product of positive affect rather than uniquely due to awe. However, such a conclusion should be tempered for a few reasons. Namely, the exploratory analyses used three variables simultaneously which overlap significantly. This renders it difficult to interpret exactly what each variable is uniquely accounting for. One task for future research may be to identify more objective measures of awe and to develop more specific and clear ways of manipulating awe.

Third, the videos used here have been widely shown to elicit awe in previous research (Valdesolo et al., 2017; Valdesolo \& Graham, 2014; van Elk, 2016). However, it may be that the experimental manipulation is actually influencing something else other than (or alongside) awe, though it is impossible to know without further research. Alternatively, they may experience some emotional state, but awe is the closest label for this experience, so the measures employed 
in such research may be non-specific. Past research has often avoided measuring other emotions (eg. Gordon, Stellar, Anderson, McNeil, Loew \& Keltner, 2016) though some research has sought to distinguish awe from other emotions (e.g. Valdesolo et al, 2017).

Further, love and pride seem somewhat associated with awe (e.g., Piff et al., 2015; Shiota et al., 2003, 2007) and indeed, they were quite consistently induced by the awe stimuli in the present studies. Future research can be undertaken to examine what other cognitive, emotional, or physiological states they arouse in viewers that may account for the effects observed here.

Fourth, it remains that the effect of condition only significantly influenced the knowledge gaps and the science interest scales. If the present effects were more general, it should have consistently influenced some of the many other outcomes included in these studies. Thus, whatever states the video arouse appear to be unique to knowledge gaps and science interest, in line with the pre-registered hypotheses and with previous theorizing on the effects of awe.

\section{Final Comments}

As Einstein (1931) said, one who never experiences awe ceases to discover. Though researchers and scientists have often speculated about the effects of awe (e.g., Valdesolo et al., 2017), the present studies represent the first empirical evidence for its effects. As researchers, we would do well to open our eyes and embrace our child-like curiosity about the world. Further, recent reports put the United States well-behind many countries in science performance (Pew Research Center, 2017) and it would be beneficial to find ways to address this. As teachers, maybe the next generation of scientists simply need to see how awe-inspiring science can be-at least these studies suggest this may be a relatively simple task.

\section{Acknowledgements}


This study was funded partially by an award from the Center for the Integration of Research, Teaching and Learning at the University of [City], and by an award from the [City] Community Foundation.

\section{Author Contributions}

[Author] designed the studies, collected the data, conducted the analyses, and wrote the manuscript. Special thanks to [advisor] for feedback and supervision, and to [colleague] for her comments on the manuscript. Special thanks to my research assistants, [names], for all of their hard work.

\section{Open Practices}

All three studies reported herein were pre-registered on the Open Science Framework prior to data collection. Pre-registered plans and materials are available at the following links: Study 1a and 1b: https://osf.io/r4ayh/?view_only=76150450c5024484aba61c1aa168336b

Study 1c: https://osf.io/ek6sy/?view_only=66be0360259340ef96c770a02e6dfa4e

Study 2: https://osf.io/3ymf5/?view_only=5e5e8a5b60eb424394672953fbfb192d

Data and syntax are available here:

https://osf.io/e734a/?view only=6f2d8d06054f41fb9c88ef5f4e100375

\section{References}

Banerjee, K., \& Bloom, P. (2015). “Everything happens for a reason”: Children's beliefs about purpose in life events. Child Development, 86(2), 503-518.

Cacioppo, J. T., \& Petty, R. E. (1982). The need for cognition. Journal of personality and social psychology, 42, 116. 
Chen, Y. Y., \& Koenig, H. G. (2006). Traumatic stress and religion: Is there a relationship? A review of empirical findings. Journal of Religion and Health, 45, 371-381.

Dunning, D. (2011). The Dunning-Kruger effect: On being ignorant of one's own ignorance. In Advances in experimental social psychology (Vol. 44, pp. 247-296). Academic Press.

Einstein, A. (1931). Living Philosophies. Simon \& Schuster: New York, NY.

Ekman, P. (1992). An argument for basic emotions. Cognition and Emotion, 6, 169-200.

Evans, E. M., \& Lane, J. D. (2011). Contradictory or complementary? Creationist and evolutionist explanations of the origin (s) of species. Human Development, 54(3), 144159.

Farias, M., Newheiser, A. K., Kahane, G., \& de Toledo, Z. (2013). Scientific faith: Belief in science increases in the face of stress and existential anxiety. Journal of experimental social psychology, 49, 1210-1213.

Feist, G. J. (2012). Predicting interest in and attitudes toward science from personality and need for cognition. Personality and Individual Differences, 52, 771-775.

Fredrickson, B. L. (1998). What good are positive emotions? Review of general psychology, 2 , 300.

Fredrickson, B. L. (2013). Positive emotions broaden and build. Advances in experimental social psychology, 47, 53.

Frijda, N. (1986). The emotions. Cambridge, UK: Cambridge University Press.

Gallagher, S., Reinerman-Jones, L., Sollins, B., \& Janz, B. (2014). Using a simulated environment to investigate experiences reported during space travel. Theoretical Issues in Ergonomics Science, 15(4), 376-394. 
Gervais, W. M. (2015). Override the controversy: Analytic thinking predicts endorsement of evolution. Cognition, 142, 312-321.

Griskevicius, V., Shiota, M. N., \& Neufeld, S. L. (2010). Influence of different positive emotions on persuasion processing: a functional evolutionary approach. Emotion, 10, 190.

Gruber, M. J., Gelman, B. D., \& Ranganath, C. (2014). States of curiosity modulate hippocampus-dependent learning via the dopaminergic circuit. Neuron, 84, 486-496.

Harty, H., \& Beall, D. (1984). Toward the development of a children's science curiosity measure. Journal of Research in Science Teaching, 21, 425-436.

Hayes, A. F. (2017). Introduction to mediation, moderation, and conditional process analysis: A regression-based approach. Guilford Publications: New York, NY.

Izard, C. E. (1992). Basic emotions, relations among emotions, and emotion-cognition relations.

Järnefelt, E., Canfield, C. F., \& Kelemen, D. (2015). The divided mind of a disbeliever: Intuitive beliefs about nature as purposefully created among different groups of non-religious adults. Cognition, 140, 72-88.

Jha, A. (2012). Stephen Hawking marks $70^{\text {th }}$ birthday with speech to leading cosmologists. Retrieved April 3 $3^{\text {rd }}, 2018$ from: www.theguardian.com.

Kashdan, T. B., \& Nezlek, J. B. (2012). Whether, when, and how is spirituality related to wellbeing? Moving beyond single occasion questionnaires to understanding daily process. Personality and Social Psychology Bulletin, 38, 1523-1535.

Kashdan, T. B., Sherman, R. A., Yarbro, J., \& Funder, D. C. (2013). How are curious people viewed and how do they behave in social situations? From the perspectives of self, friends, parents, and unacquainted observers. Journal of personality, 81, 142-154. 
Keltner, D., \& Haidt, J. (2003). Approaching awe, a moral, spiritual, and aesthetic emotion. Cognition \& emotion, 17, 297-314.

Lombrozo, T., Shtulman, A., \& Weisberg, M. (2006). The Intelligent Design Controversy: Lessons From Psychology and Education. Trends in Cognitive Sciences, 10, 56.

McPhetres, J., Nguyen, T.T. (2017) Using findings from the cognitive science of religion to understand current conflicts between religious and scientific ideologies. Religion, Brain \& Behavior. doi:10.1080/2153599X.2017.1326399

Pew Research Center (2014). Worldwide, many see belief in God as essential to morality. Accessed December 31, 2015 at: www.pewforum.org.

Pew Research Center (2015). U.S. public becoming less religious. Accessed June 18, 2017 from: www.pewforum.org.

Pew Research Center (2017). U.S. student's academic achievement still lags that of their peers in many other countries. Accessed June 18, 2017 from: www.pewforum.org.

Piaget, J. (1971). Genetic epistemology. New York, NY: Norton Library.

Piedmont, R. L. (1999). Does spirituality represent the sixth factor of personality? Spiritual transcendence and the Five-Factor Model. Journal of Personality, 67, 985-1013.

Piff, P. K., Dietze, P., Feinberg, M., Stancato, D. M., \& Keltner, D. (2015). Awe, the small self, and prosocial behavior. Journal of personality and social psychology, 108, 883.

Preston, J., \& Epley, N. (2009). Science and God: An automatic opposition between ultimate explanations. Journal of Experimental Social Psychology, 45, 238-241.

Preston, J. L., Ritter, R. S., \& Hepler, J. (2013). Neuroscience and the soul: competing explanations for the human experience. Cognition, 127, 31-37. 
Schraw, G., \& Dennison, R. S. (1994). Assessing metacognitive awareness. Contemporary educational psychology, 19, 460-475.

Shariff, A. F., Cohen, A. B., \& Norenzayan, A. (2008). The devil's advocate: Secular arguments diminish both implicit and explicit religious belief. Journal of Cognition and Culture, 8, 417-423.

Shiota, M.N., Campos, B. \& Keltner, D. (2003). The faces of positive emotion. Prototype displays of awe, amusement, and pride. Annals of the New York Academy of Sciences, 1000, 296-299, doi: 10.1196/annals.1280.029

Shiota, M. N., Keltner, D., \& Mossman, A. (2007). The nature of awe: Elicitors, appraisals, and effects on self-concept. Cognition and emotion, 21, 944-963.

Toplak, M. E., West, R. F., \& Stanovich, K. E. (2014). Assessing miserly information processing: An expansion of the Cognitive Reflection Test. Thinking \& Reasoning, 20, $147-168$.

Valdesolo, P., \& Graham, J. (2014). Awe, uncertainty, and agency detection. Psychological science, $25,170-178$.

Valdesolo, P., Park, J., \& Gottlieb, S. (2016). Awe and scientific explanation. Emotion, 16, 937940.

Valdesolo, P., Shtulman, A., \& Baron, A. S. (2017). Science is awe-some: The emotional antecedents of science learning. Emotion Review, 9, 215-221.

Van Cappellen, P., \& Saroglou, V. (2012). Awe activates religious and spiritual feelings and behavioral intentions. Psychology of Religion and Spirituality, 4, 223. 
van Elk, M., Karinen, A., Specker, E., Stamkou, E., \& Baas, M. (2016). 'Standing in Awe': The Effects of Awe on Body Perception and the Relation with Absorption. Collabra: Psychology, 2.

Wallace, B.C., Dahabreh, I.J. Trikalinos, T.T., JLau, J., Trow, P., \& Schmid, C.H. (2012).

Closing the Gap between Methodologists and End-Users: R as a Computational BackEnd. Journal of Statistical Software 49, 1-15. 